\title{
Glaucoma Surgery with Fugo Blade
}

\author{
Daljit Singh and Richard Fugo \\ Guru Nanak Dev University \\ India
}

\section{Introduction}

Glaucoma has protean presentations. It strikes at any age. Before 1902 when Elliot started the first " trephine" filtration, the only surgery available was "broad iridectomy". This undoubtedly helped angle closure cases. Trephine was a filtration revolution.The anesthesia was $4 \%$ cocaine as drops. Facial and retrobulbar blocks came to be used in mid-fifties. Trephine, "iridencleisis" and "scleral punch" were commonly performed operations in sixties. Cairns started "trabeculectomy" in 1968. Non-perforating glaucoma surgery was proposed in 1984. Lasers, Glaucoma drainage devices and Viscocanalostomy are recent. Transciliary Filtration was first presented by Singh at Ophthalmological Society of UK in 1979 for cases of intractable glaucoma.

\section{The myth of guarded surgery:}

Innovation in glaucoma surgery is limited by the available surgical tools which allow reaching the aqueous pool by dissecting through the layers and sub-layers of the tissues, which are sutured in the end. Extensive surgery encourages scar failure leading to failure. Therein enter anti-mitotic agents.The word "guarded" has become a watchword for every kind of glaucoma surgery, since Cairn's trabeculectomy. Actually, we have two guards- the conjunctiva and the scleral flap They prevent excessive outflow of the aqueous and prevent bacterial entry. The tears clean the conjunctiva with every blink. The thickness of the conjunctiva is the most important defense. If it is thin and stretched, there may develop a crack through which the bacteria can gain entry, resulting in bleb infection and endophthalmitis. The point is, if the conjunctival wall is breached, the "guarded" scleral flap is of no help. Thus the guarding role of a scleral flap seems merely an illusion, fortified over decades by repetition. The OCT pictures below compare a cystic bleb with a non-cystic bleb.

The other function of the supposed "guard" is to control the aqueous outflow to a "desired" normal level. Despite many manual, laser and anti-mitotic tools there remains an uncertainty about the final result. There are too many operative and postoperative variables that prevent clear understanding of the overall picture. The myth of "guarded" filtration needs to be kept in mind.

Fugo blade as described later, changes the rules of the game. No layer by layer dissection is needed. A precise channel can be easily made directly between the subconjunctival tissues and the aqueous chamber ( anterior or posterior). ab externo or ab interno. The number of variables get reduced. There is minimal trauma to the tissues. 


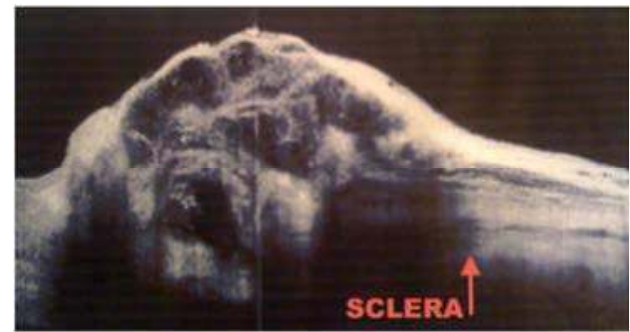

Fig. 1. OCT of a cystic bleb following trabeculectomy, a guarded surgery. The covering conjunctiva is thin. The sclera distal to the arrow has disappeared.

Or has it fragmented in the cystic bleb?

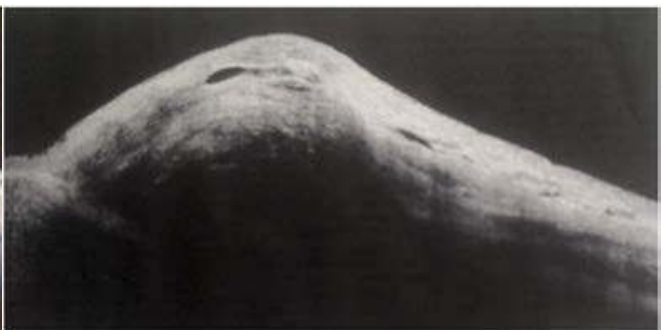

Fig. 2. OCT of a bleb following "unguarded" Transconjunctival Transciliary Filtration(TCF). The covering conjunctiva is thick.

\section{An ideal bleb}

The following definition was given by Pollak ( 2000)."The ideal bleb is ischemic, cystic, moderately elevated and has a moderately thin wall. IOP stays between $6 \mathrm{~mm} \mathrm{Hg}$ and $12 \mathrm{~mm}$ $\mathrm{Hg}$. The patient remains comfortable, has no pain and the bleb remains hidden beneath the upper eyelid." (Italics are ours). The definition holds till today.

A bleb starts metamorphosis from day one. Pressure gradient between the anterior chamber and the subconjunctival fluids and lymphatics (to be described later) is determined by the diameter and length of the filtration track and the tissue resistance created by the connective tissue. In a two months old Transconjunctival Transciliary Filtration (to be described later) bleb shown in Fig. 3 the tenon capsule and conjunctiva are seen lifted together. The tenon capsule looks spread out and spongy . The conjunctival lymphatics appear to be working . IOP is $12 \mathrm{~mm}$. When pressure is applied on the eyeball, the tenon capsule gets compressed and its fluid moves in to the lymphatics under the conjunctiva. As a result the earlier visible lymphatics swell up and newer lymphatics open up. Later on the bleb wall might consolidate. Every bleb has its own OCT life story to tell. Raised blebs, not congested at the edges usually belong to the successful surgeries.
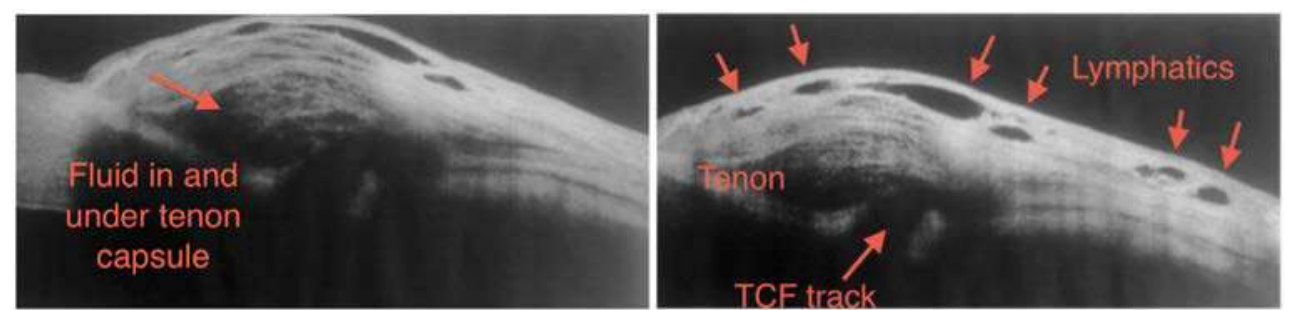

Fig. 3. A 2 months old bleb, is still spongy, after Transconjunctival Transciliary Filtration (TCTCF). Compressing the eyeball reduces fluid in tenon capsule and fills up the lymphatics and opens many new ones.

\section{The functioning of the bleb}

Bleb formation is an important event. The following ways of fluid disposal have been suggested from time to time, based on papers written in fifties and seventies (Allingham 2005): 1. The fluid usually filters through the conjunctival bleb wall and mixes with the tear film 
2. The fluid is absorbed by vascular and peri-vascular conjunctival tissue.

3. The fluid is carried away in degenerated veins.

The out coming fluid cannot be absorbed. It has to be drained. There is a vehicle available for drainage, the lymphatics. (Singh 2002,2003). The demonstration of lymphatic system under the conjunctiva, changes the rules of the game. Their surgical destruction goes against the grain/character of the eye.

\section{The living anatomy of the posterior chamber}

The anatomy of the posterior chamber is important, when there is a technique to drain the posterior chamber, the "Transciliary Filtration" (TCF) or "Singh Filtration".

The posterior chamber is between the iris and the anterior surface of the lens and the zonule. It is triangular on cut section, the apex at the pupil, and the base at the ciliary body. The base has two parts, the anterior smooth ciliary sulcus and the posterior ciliary process. There are in all 70-80 ciliary processes, the width of the anterior most part of each, the head, being $0.2 \mathrm{~mm}$, length $2.0 \mathrm{~mm}$ and height 0.8 to $1 \mathrm{~mm}$. There are valleys between the processes, which contain smaller processes. The distance between the main ciliary processes is generally more than $0.3 \mathrm{~mm}$ with some plus or minus. The width of the ciliary sulcus, the part between the root of the iris and the head of the ciliary process is about $0.7 \mathrm{~mm}$. The ciliary processes are held in place in the phakic eyes by the zonular fibers.These measurements are critically important for TCF surgery.

\section{The importance of UBM}

Ultrasound bio-microscopy provides invaluable information about the anatomy of the posterior chamber. It shows the presence and extent of the ciliary processes. It is possible to measure the width of the lateral wall of the posterior chamber as well as the distance that the ablating Fugo blade tip shall travel to reach the posterior chamber. In failed glaucoma surgery cases, it provides information on the location and extent of filtration track closure.

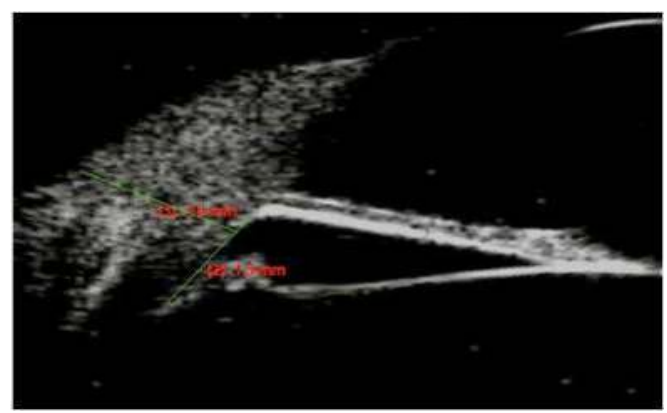

Fig. 4. The base of the posterior chamber is about $1.9 \mathrm{~mm}$, out of which the ciliary sulcus accounts for about $0.8 \mathrm{~mm}$, the ciliary process occupies rest of the wall.The distance from the surface of the eye to the posterior chamber is about $2 \mathrm{~mm}$.

\section{Surface anatomy and trans-illumination}

The limbus shines through the conjunctiva. The posterior edge of the limbus can be visualized. A vertical incision at this place shall open in to the anterior corneo-scleral trabeculae. For doing a TCF operation, we need to choose a point about $1.5 \mathrm{~mm}$ from the limbus. This point shall be beyond the canal of Schlemm, over the anterior part of the ciliary body. For making a TCF 
track correctly, critical judgement is needed to take a correct route to the posterior chamber. The variation in the depth of the anterior chamber can create an error of judgement. A deep anterior chamber means that the angle recess is far away than one might expect. To see the angle recess and the anterior part of the ciliary body, the ideal tool is trans-illumination. The light pipe of a strong light source, or a strong fiber light, sterilized chemically or in ETO, is brought close to the limbus. The microscope light is switched off. Transillumination helps to positively identify the anterior end of the ciliary body. A point is marked on the sclera at that point. TCF shall be started about $1 \mathrm{~mm}$ posterior to this point.

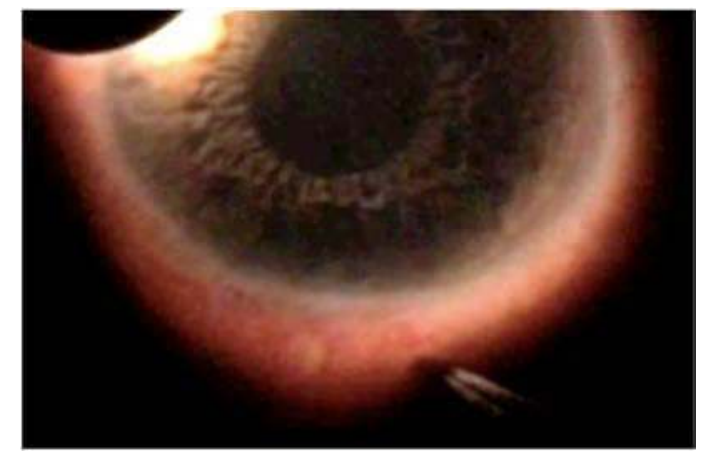

Fig. 5.Transillumination through a light pipe, helps in defining the end of the ciliary body and the beginning of the angle of the anterior chamber. A forceps is making an indentation on the dividing line.

\section{The anatomy of the limbus}

Our technique of Microtrack Filtration (MTF, to be described later) in to the anterior chamber demands a closer look at the limbus. The tenon capsule under the conjunctiva is said to attach to sclera a short distance proximal to the conjunctival attachment to the limbus. Thus there is a small pre-tenon subconjunctival space. If Microtrack Filtration is made far enough, it shall reduce the chances of tenon capsule reactions. MTF is ordinarily available to inspection only on gonioscopy. An anteriorly directed MTF track gets made in the clear cornea and is visible for inspection without a goniolens.
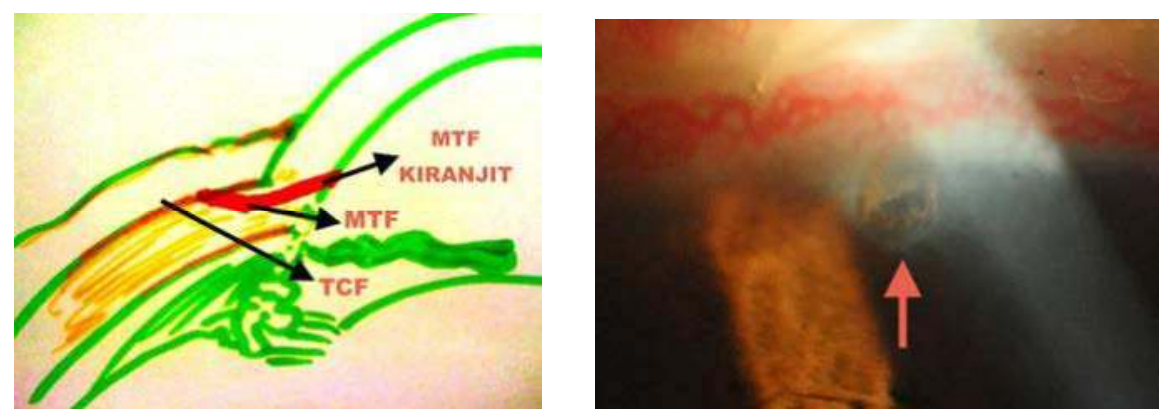

Fig. 6. Diagrammatic anatomy of the limbus and its relationship to TCF,MTF and MTF (Kiranjit).Note the angles of entry in each case. In a postoperative picture ,MTF-K internal opening is directly visible and is clearly away from the iris. 


\section{Conjunctival lymphatics}

We base our glaucoma surgery on the understanding that an extensive network of lymphatics exists under the conjunctiva and that it plays a role as flood channels to drain the out coming aqueous after any kind of filtration surgery (Kent 2002,Bethke 2002,Singh 2002,2003). Therefore this network should be preserved during all filtration operations. Manual dissections and bipolar cautery definitely destroy them. With OCT we can observe lymphatics in vivo. It is easy to find out their state of filling. The conjunctival lymphatics can be demonstrated in many different ways. Once they are seen, their importance becomes evident.

\section{Lymphatics on Slit Lamp Examination}

1. The corrugation of the light reflex from the conjunctiva is produced by the parallel running lymphatics.

2. If there is pigment around the limbus, the lymphatics stand out as tubular structures. Their corneal ends disappear in to the cornea, while proximally they are interconnected and are finally joined to larger channels running parallel to the limbus.

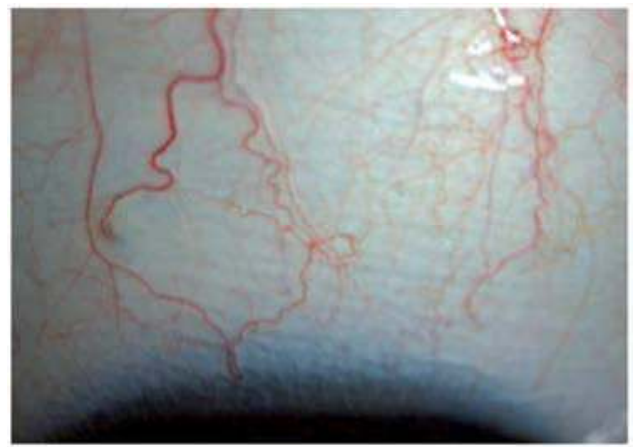

Fig. 7. Raw lymphatics running parallel to the limbus.

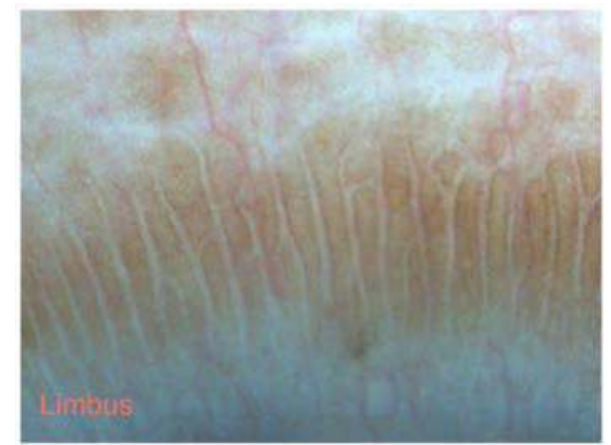

Fig. 8. The limbal lymphatics enter singly perpendicularly in to the cornea. They anastomose proximally and open in to the bigger parallel running lymphatics.

\section{Demonstration of lymphatics on operating table:}

The lymphatics can be easily demonstrated by injecting trypan blue in the periphery of the cornea, under the limbal conjunctiva, through a 26 to 29 gauge disposable needle. The injection is given through small strong pushes of the piston. The lymphatics start filling. In spreading. A whole network of lymphatics can be charted.

In cases of failed glaucoma surgery, the scarred tissues show no lymphatics and the nearby areas they are thin, beady and end as knobs.

Sclero-conjunctival lymphatics: A post VR and silicone surgery young patient had glaucoma. He also had a silicone tire on the sclera. His perilimbal conjunctiva lacked thickness and the sclera looked naked. To study lymphatic architecture in this area, trypan blue dye was injected in to the sclera close to the limbus. The dye traveled inside the scleral channels along the limbus and appeared as multiple blobs along the limbus The most 
revealing thing was that the dye also traveled posteriorly ,inside the sclera, till it got under the normal conjunctiva, where it entered in to conjunctival lymphatics. This proves that a closed system of lymphatic channels exists between the sclera and the conjunctiva. If you couple it with the recent demonstration of lymphatics in ciliary body ( Yeni et al 2009), the inescapable conclusion is that uveo-scleral outflow is not by diffusion as commonly expressed, but through a system of channels.
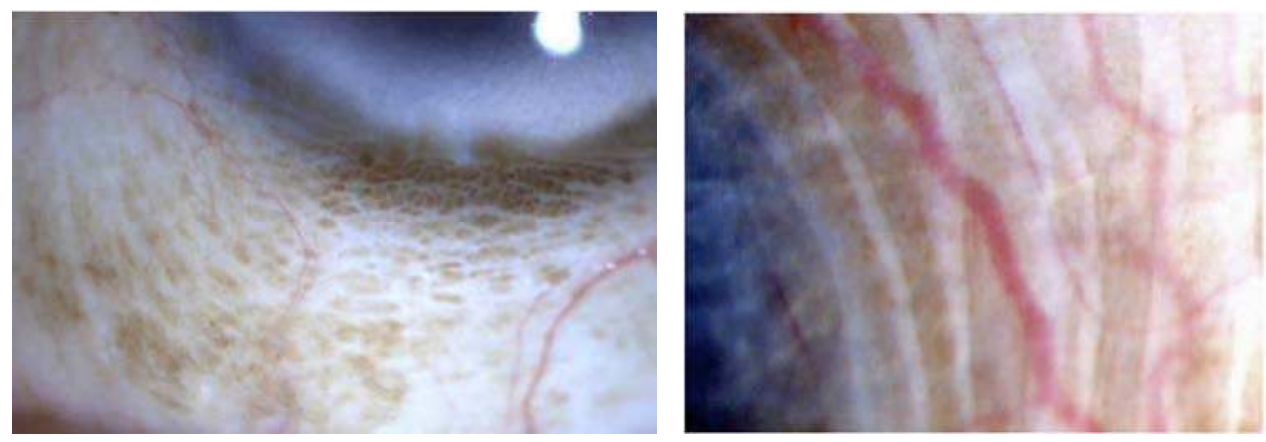

Fig. 9. The network of lymphatics has been beautifully outlined by subconjunctival pigment.

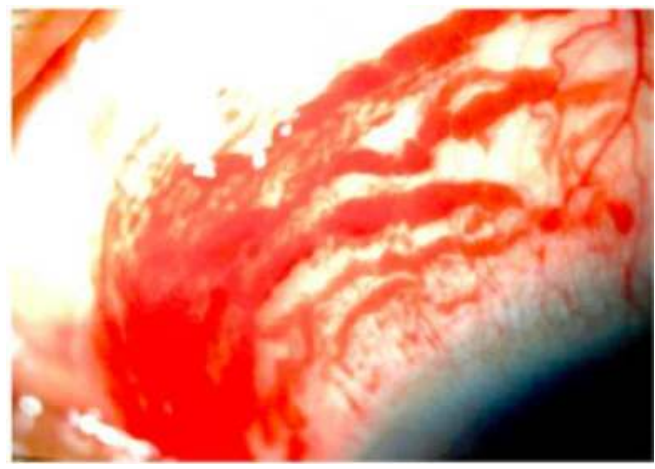

Fig. 11. Blood in lymphatics as a result of surgical trauma. The finest vessels are at the limbus and the widest are away from limbus.
Fig. 10. A rare picture of lymphatics. Rivulets of lymphatics around the limbus are beautifully outlined by the pigment. The blood vessels show paling of color, where they are crossed anteriorly by the lymphatics.

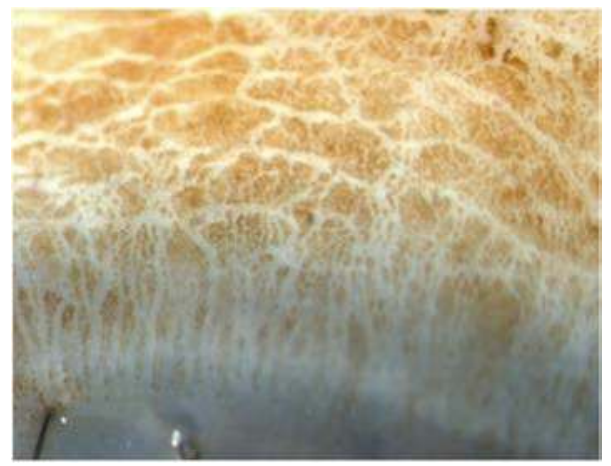

Fig. 12. The whole conjunctival landscape is filled with a system of lymphatics, in a very orderly fashion. 

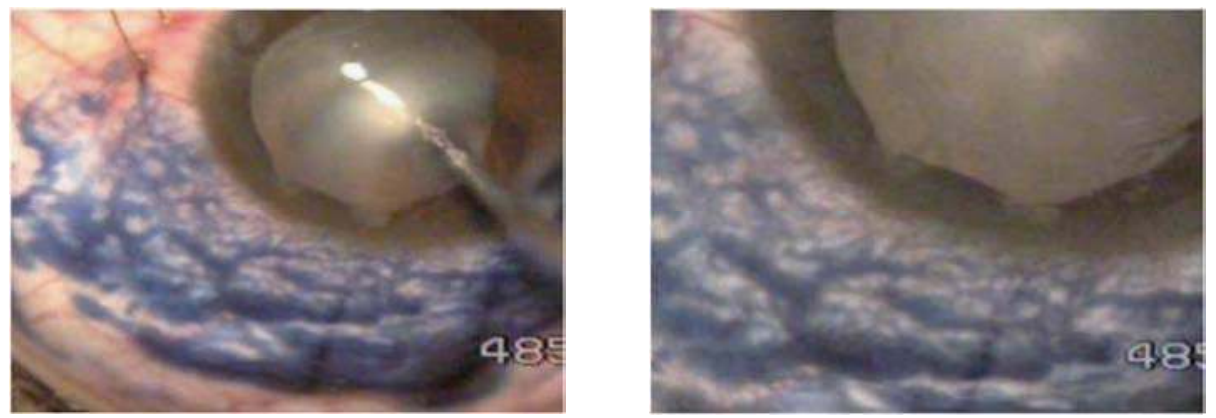

Fig. 13. Extensive network of lymphatic channels charted by injecting trypan blue at the limbus.

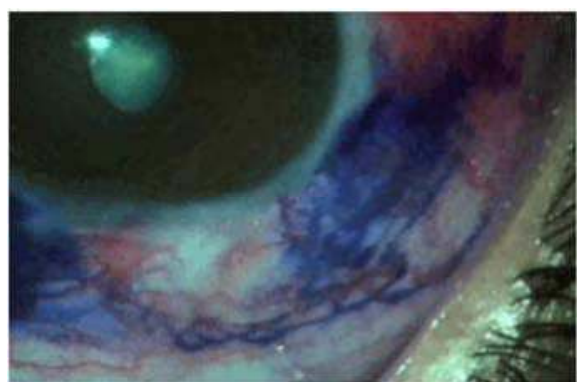

Fig. 14. A failed case of trabeculectomy. Dye injection fails to show lymphatics in the totally scarred central area. The seen lymphatics are thin have a disturbed pattern.

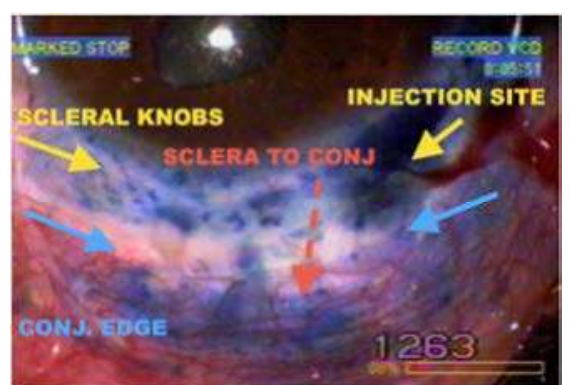

Fig. 15. It demonstrates the intrascleral movement of injected trypan blue along the limbus where it ends in knobs. The proximal movement of the dye through the sclera enters the subconjunctival lymphatics, proving that conjunctival and scleral channels are one system.

Here is the film which demonstrates the connection between the scleral channels and the subconjunctival lymphatics.

http://www.youtube.com/watch?v=iAGXQWzQHPA

\section{Mitomycin and lymphatics}

The following pictures provide slit lamp and OCT proofs of the existence of lymphatics. What is seen on an optical section is confirmed by an OCT (also a section). Much more important is the fact that the lymphatics look healthy and functioning, a month after exposure to $0.01 \%$ of mitomycin C (MMC). During surgery a big bleb of MMC was raised around the outer end of MTF channel. Injected MMC was left as such and no attempt was made to wash it out. It appears that lymphatics can withstand exposure to mitomycin $C$. What would happen if all lymphatics were to be destroyed by mitomycin C? The out coming fluid would not move at all. Recall what happens in angioneurotic edema, when the lymphatics become temporariy overloaded. 

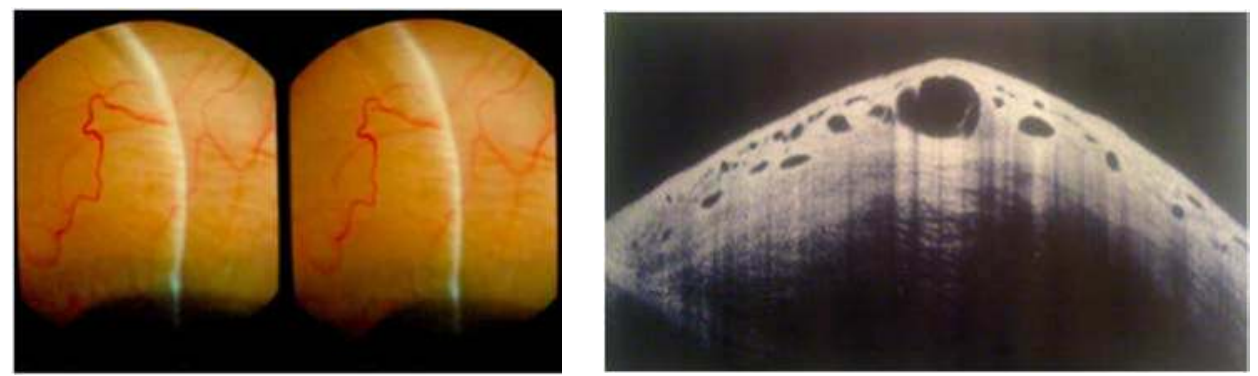

Fig. 16. A 35 years old case of MTF, shows the presence of filled lymphatics under the conjunctiva, one month after surgery, both on slit lamp optical section and with OCT. The OCT image is particularly striking. IOP is $9 \mathrm{~mm}$, down from $35 \mathrm{~mm}$.

Below is another case, a 12 years old boy who was operated for steroid glaucoma more than one year back. In this case $0.02 \%$ MMC was deposited around MTF channel. Slit lamp examination shows the presence of normal lymphatics. On the OCT, they appear in collapsed (un-stressed) state. His IOP is $16 \mathrm{~mm}$ without medication.
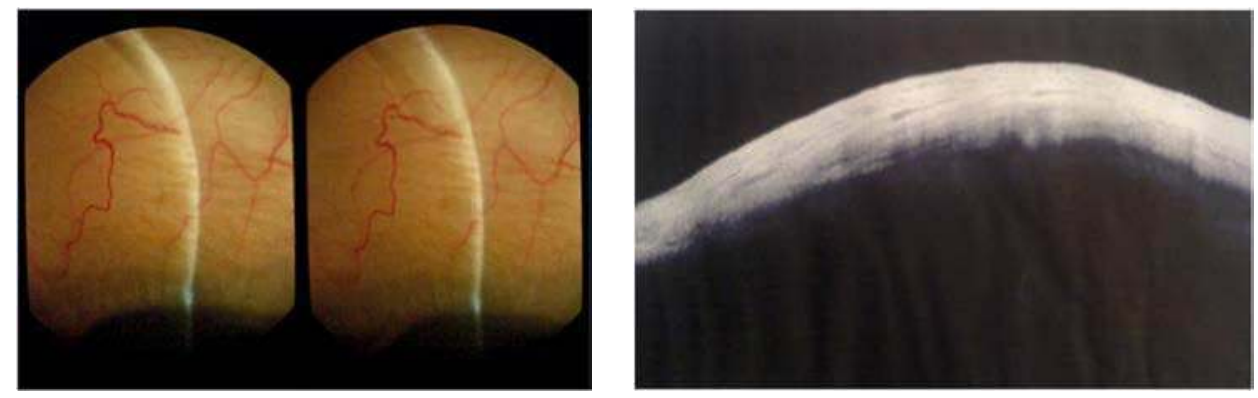

Fig. 17. One year after MTF and $0.02 \%$ MMC deposition in a 12 years old boy. The slit lamp examination picture clearly shows the presence of lymphatics. OCT shows them to be in a flattened state.

\section{Posterior chamber drainage}

Since a major technique with Fugo blade is posterior chamber drainage, it is appropriate to consider a few salient points. Posterior chamber drainage may be performed after making conjunctival-tenon flap, followed by track making through the sclera and ciliary body. It is then called "Transciliary filtration" or TCF. It may be transconjunctival, i.e. without flap making dissection, when it is called "Transconjunctival Transciliary Filtration" or TCTCF.

TCF or TCTCF can be performed with a $6 \mathrm{X}$ operating loupe or under an operating microscope. A loupe is also convenient for doing surgery in far off places, devoid of electricity. A coaxial illumination is not necessary. TCTCF takes less than a minute to perform. The anterior chamber remains formed at the end of the surgery. Iridectomy is not done. TCTCF allows a measured concentration of mitomycin to be deposited around the filtration channel as a balloon of any desired size. There is no need to wash it out. There is no danger of bleb leakage. TCTCF caused conjunctival hole can be closed with one suture. It makes a small foot print on the sclera and other tissues. Therefore re-surgery is easy. 


\section{Fugo blade}

Fugo blade (Winn 2001,Eisenstein 2003,Ronge 2003,Fugo 2005,Guttman 2005,2009,McGrath 2008 ) is a new operating tool, that produces "laser like plasma" on the operating blunt metal wire tip. It works on 4 rechargeable battery cells. Total cut time of one charge is 40 minutes. Numerous glaucoma operations can be done after one charge. It is FDA approved device for capsulotomy, iridectomy and glaucoma (Transciliary Filtration). Cut power and cut intensity can be adjusted from the console.

How does Fugo blade work?

It functions like this. First, it focuses electro-magnetic waves to one point, i.e. the tip of the instrument. Secondly, the energy is tuned to the tissues by the process of resonance. The moment a tissue is touched by the activated tip, the plasma energy gets transferred to the molecules of the tissue. Note that there is transfer of energy to the molecules, therefore the Fugo blade comes in the domain of nano-technology. When tissue molecules absorb plasma energy, they go to higher energy levels, thereby becoming unstable. The unstable molecules explode in the same fashion as excimer laser explodes corneal tissue molecules. The exploding molecules carry with them water from the tissue and produce a plume, which gives a peculiar aromatic smell. The molecules/tissue split in the line of incision/ablation, without bleeding, since the blood vessels are also ablated from the path. It is obvious that Fugo blade provides a fundamentally new cutting energy, the plasma. It is so different from the electrosurgical devices that we are familiar with (Guttman 2005).Fugo blade makes it possible to ablate surfaces and to create channels/tracks in one or multiple tissues in one single movement. This helps to perform new operations described here.

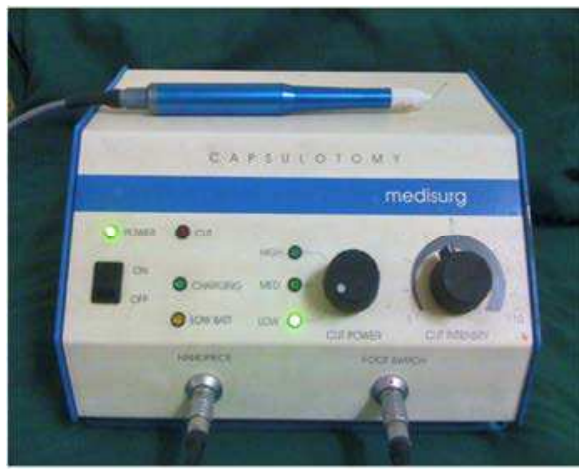

Fig. 18. Fugo blade console, the hand piece and the operating tip. The cut power can be varied in 3 steps and cut intensity can be adjusted in 10 steps.

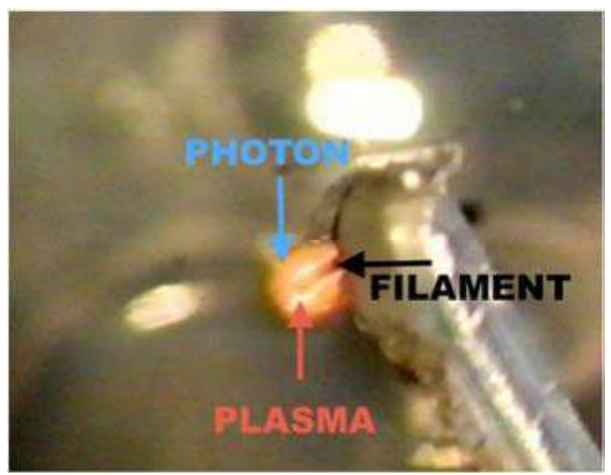

Fig. 19. Showing high power view of the plasma. The yellow-white cutting plasma surrounds the steel filament. The surrounding orange cover is non-cutting photonic cloud.

The beauty about the plasma is that it becomes visible, the moment it touches the tissues. Looked under a high power microscope, one can see a yellow white coating of plasma on the steel filament. There is a constant movement like you see on an active beehive. The plasma is surrounded by orange light, the photonic cloud. The cutting power resides only in the plasma cloud. The width and the power of the plasma is controlled from the controls of 
"power" and "intensity". The plasma width may be kept at 25, 50 or 75 microns. With this kind of plasma cloud, it is possible to make precisely measured filtration channels.

The cutting/ablation by Fugo blade is not accompanied by clinically visible collateral damage. This fact is corroborated by microscopic and electron microscopic studies on the lens capsule, cornea and other tissues (Fine 2002,Wilson 2003,Izak 2004, Trivedi 2006.Peponis2006), It is just as you would expect from an excimer laser.

\section{Filtration techniques with Fugo blade}

"Transciliary Filtration" was first presented by the author (DS) as a manual technique for intractable cases of glaucoma at Ophthalmological Society of United Kingdom in 1979. From 1993 to 1999, it was done with erbium laser. From 2000 onwards, Fugo blade was the tool .

\section{Transciliary Filtration (Singh)}

In open TCF, a conjunctival flap is made- fornix based or limbal based(Singh 2002,Kent 2002, Fugo 2002, 2005,2007, Guttman 2005,Scimeca 2005,Atwal 2005 and Dow 2008). The bleeding points are either allowed to stop spontaneously, or they are touched with 600 micron Fugo blade tip at low energy. Transillumination may be done to visualize the shining angle recess and the anterior limit of the ciliary body. A mark is made on the sclera, usually about 1.5 $\mathrm{mm}$ from the posterior edge of the limbus,or $1 \mathrm{~mm}$ proximal to the visualized angle recess. The 600 micron Fugo blade tip is used to ablate a scleral pit, by ablating a little at a time, till ciliary body is reached. The posterior edge of the scleral pit is beveled with the same tool, that helps in the next step. A 300 micron tip is rested on the scleral bevel and directed towards the posterior chamber. It is allowed to ablate the ciliary body a little bit at a time, till it reaches the posterior chamber, which is announced by the outpouring of aqueous. The tenon-conjunctival flap is closed with sutures. Mitomycin if so desired, can be applied before entering the posterior chamber,to the scleral pit only, or more widely and under the conjunctiva. The anterior chamber does not collapse. In angle closure cases, the anterior chamber actually deepens. The postoperative management aims at reducing/preventing inflammation and keeping a look out for a failure or a complication.

Here is a film showing open TCF in a case of uveitic glaucoma. In this case TCTCF had failed 2 times.

http:/ / www.youtube.com/watch?v=kUMgN17JNOs

\section{Transconjunctival Transciliary Filtration (Singh)}

TCTCF is far less traumatic. The surgery is astigmatically neutral like TCF.

Anaesthesia: Subconjunctival injection of lignocaine $2 \%$ with adrenaline.

Surgical steps are as follows:

1. Exposure of the eyeball- a wire speculum is needed.

2. Eye fixation: An epi-scleral suture is passed close to $10 \mathrm{O}^{\prime}$ clock or $2 \mathrm{O}^{\prime}$ clock limbus, is held with a light weight clamp.

3. The mobility of the conjunctivais tested. In case the conjunctiva appears stretched, a smaller speculum is used.

4. Marking a spot from where TCTCF shall be performed. One way is to mark a point on the sclera $1.5 \mathrm{~mm}$ posterior to the limbus. The sclera is pressed with the tip of a forceps to create a dent. Another way is trans-illumination of the limbus with a fiber light, which defines the position of the angle recess and the ciliary body. The tip of the 
forceps is pressed $1 \mathrm{~mm}$ posterior to it. The surgeon perceives in his mind's eye the relation of this point in to the lateral wall of the posterior chamber. A UBM view of the posterior chamber, if available, gives greater confidence. UBM is especially useful in aphakic/pseudophakic eyes.

5. A blunt edged instrument is used to create a linear gutter at the chosen point, parallel to the limbus. For this purpose, we can use a blunt hockey stick knife or Took's knife.. It should make a deep dent on the sclera without cutting the overlying conjunctiva.

6. From the fornix side, the conjunctiva is pushed towards the limbus, till the pusher blade is stopped at the scleral gutter just produced. This blade shall tie down the conjunctiva till TCTCF has been completed. This blade has to be non-metallic. The best instrument is a blunted $1.5 \mathrm{~mm}$ wide, 45 degree sapphire knife.

7. The conjunctiva close to the pusher is dried, with a sponge.

8. A 300 or 500 micron Fugo blade tip is chosen. A medium cut power and high intensity mode is selected on the console. The tip is pressed on the conjunctiva without activation. Now, the surgeon needs great concentration of mind and steadiness of the hand. The distance to be traveled is short, about 1 to $1.5 \mathrm{~mm}$ and the ablating power of the Fugo blade is great. The foot switch is pressed for a fraction of a second. The conjunctiva is ablated instantly and cavitation bubbles fly under the conjunctiva. Do not be distracted. Take out the tip, while holding down the conjunctiva as before. Go through the conjunctival opening and reach the sclera. Ablate the scleral channel, bit by bit. Ablate a little, withdraw the tip and go back again. Keep the orientation focused towards the lateral wall of the posterior chamber. The last time the tip is activated and withdrawn, fluid is seen following it. Some ciliary pigment is also seen in the out coming fluid.The mantra of TCTCF is - place the tip in position without pushing, activate and withdraw. Next time, go back till obstructed, stay without push, activate and withdraw.

9. A drop of trypan blue is put on the out flowing fluid, it gets washed away, confirming that the aqueous is flowing.

10. As a rule the anterior chamber does not collapse. In cases of angle closure glaucoma, the depth actually increases.

11. Wait for the fluid flow to slow down. Mitomycin $C$, in concentration anywhere between $2 \mathrm{mg}$ in $10 \mathrm{ml}$ saline ( $0.02 \%)$ to $100 \mathrm{ml}$. saline $(0.002 \%)$, is injected with a cannula, to raise a balloon about $8-12 \mathrm{~mm}$ wide at and around the scleral end of the filtration track. No attempt is made to wash it.

12. A single fine suture is applied to the conjunctival hole through which surgery was done.

13. The eye is closed with a tape and a shield. No pad is placed underneath it.

\section{Most important precaution during TCTCF}

The most important cause of TCTCF early failure is a blood clot that can close the filtration channel. A blood ooze is seen in about $5 \%$ cases. Wait till the blood ooze stops. One can repeatedly irrigate the anterior chamber, the fluid shall come out of the TCF track. Irrigation is repeated till every trace of blood has disappeared. The following film shows such a case.

http:/ / www.youtube.com/watch?v=MO0N0-wzG8Q

4 hours later the eye was examined under a slit lamp and OCT was done. The bleb is clear of the blood and the OCT shows a clear TCF track. 

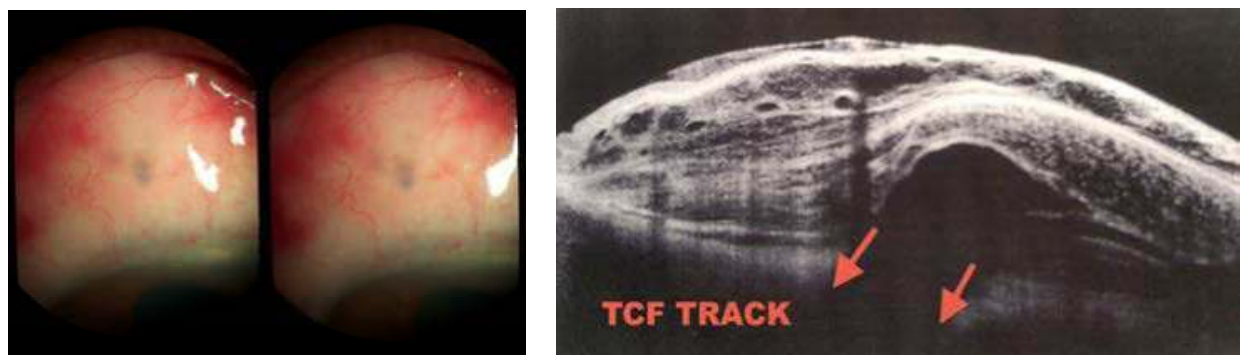

Fig. 20. Shows the bleb and OCT 4 hours after TCTCF surgery. The filtration area is clear.

Here are two more films showing TCTCF:

http://www.youtube.com/watch?v=deLKpc6MISY

http://www.youtube.com/watch?v=Fa9g5r9zMSg

\section{Postoperative management:}

The eye is opened after 4 hours. Antibiotic-steroid drops are instilled 6-8 times a day. A steroid-antibiotic eye ointment is applied at bedtime. The repeat visit is after 2 days, 2 weeks and subsequently every 2 months. The anterior chamber problem like flat anterior chamber is nil. Hyphema can occur in cases of neovascular glaucoma. Choroidal detachment is rare. Results: We have been doing TCF since year 2000. Since then we have performed over 3500 operations. Preoperatively, most of our patients have intraocular pressure in high thirties or forties. For the first 5 years Mitomycin was applied occasionally. The failure rate in primary operations was around $20 \%$. Nearly half the failed cases needed surgery, while the rest were controlled by local medication. With the current technique of TCTCF with a 500 micron Fugo blade and subconjuncival deposition of $0.01 \%$ mitomycin at the end of surgery, the re-surgery rate is $4 \%$ in primary glaucoma.

\section{Postoperative appearances}

A few examples are given below:
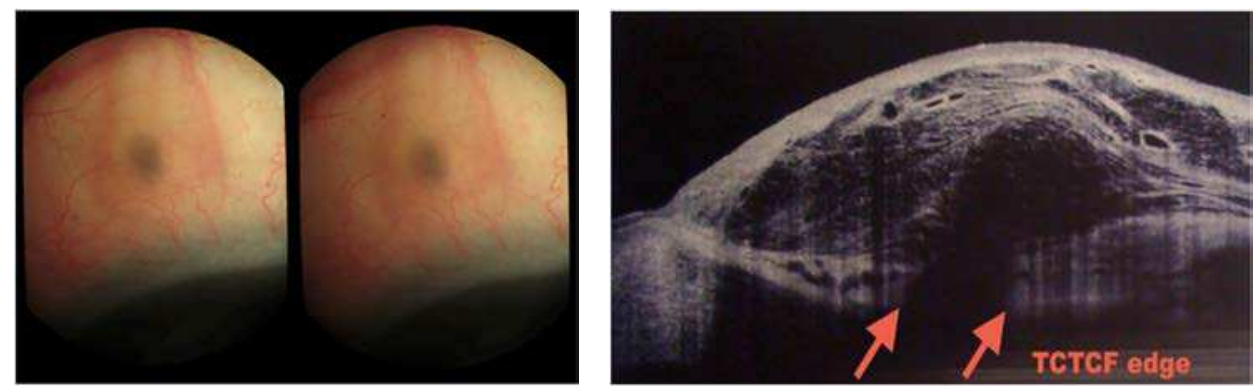

Fig. 21. A patient of TCTCF, one day after surgery. The bleb is borderless, well formed and its contents are transparent. The vessels of the conjunctiva and episclera appear intact. OCT picture shows the scleral mouth of TCF channel, spread out tenon capsule and prominent lymphatics. 

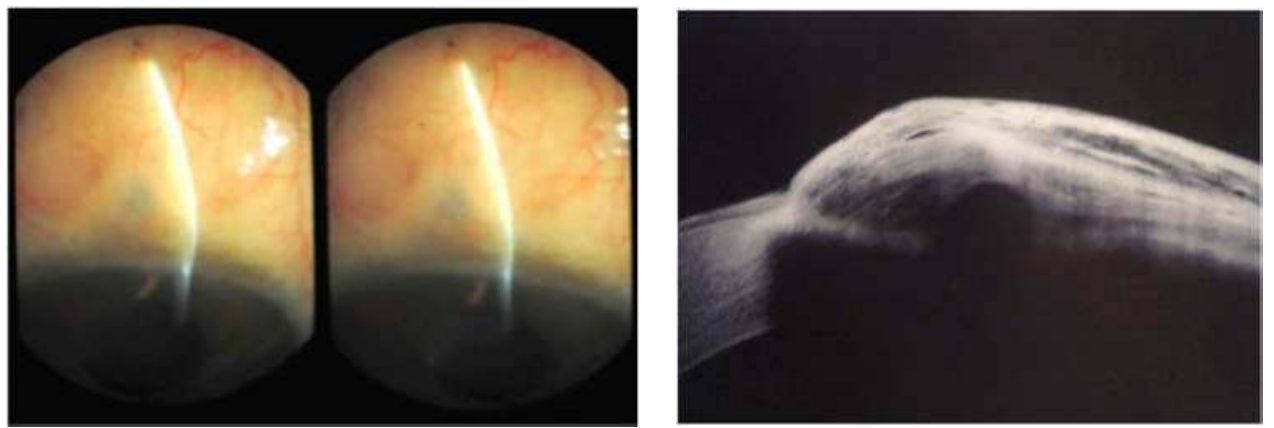

Fig. 22. TCTCF in a 65 year old, 4 months after the surgery. The bleb wall is condensed and is normal for thickness.

\section{Microtrack Filtration (Singh)}

Microtrack Filtration (MTF) connects the anterior chamber to the near limbus subconjunctival space (Singh 2001,2002). This technique is ideally suited for cases with deep anterior chamber, as are found in buphthalmos, youth, trauma, aphakes and pseudophakes. MTF causes minimum or nil trauma to the tenon capsule. The track/channel is so made that it opens anterior to the angle of the anterior chamber. A 100 micron Fugo blade tip is used for this purpose. By varying the energy a filtration track of 150 or 200 micron can be produced. The steps of operation are :

1. The eyeball is fixated as described above. The mobility of the conjunctiva is tested with a cotton bud. The limbus and the conjunctival attachment are visualized. The track is to be made close to the conjunctival attachment.

2. The conjunctiva is pulled or pushed towards the conjunctival root/attachment, such that a point can be found and marked as a depression, through which the ablating tip shall pass. This may be done with the tip of a forceps.

3. The eyeball is stabilized by pulling the conjunctiva with a utility forceps.The other way is to push and stabilize the conjunctiva with a blunt sapphire knife and then complete the surgical steps.

4. Fugo blade 100 micron glaucoma tip is suitably bent by the surgeon himself to make it ergonomic. It is placed at the desired point on the outside of the limbus in an inactivated state. A very slight pointed pressure is made in the desired direction. The energy on the console is low cut power at high intensity. The moment the foot switch is pressed, the tip passes/ablates through the conjunctiva and limbus in to the anterior chamber. To keep the speed of penetration slow attempt is made to advance it in fractions, by fast switch on and off.

5. As the tip is withdrawn, the anterior chamber fluid rushes out. The conjunctiva is held in place. Carbachol and air are injected in to the anterior chamber.

6. The conjunctiva is allowed to retract to its normal place. The out coming aqueous starts raising a bleb. Mitomycin C $0.005 \%$ or $0.01 \%$ is deposited as a balloon on and around the outer end of the newly formed channel.

7. The conjunctival hole is sutured.

8. A bandage contact lens is placed. The swollen conjunctiva at the upper limbus prevents it from covering it. But as the bleb recedes, it shall slip upwards. 


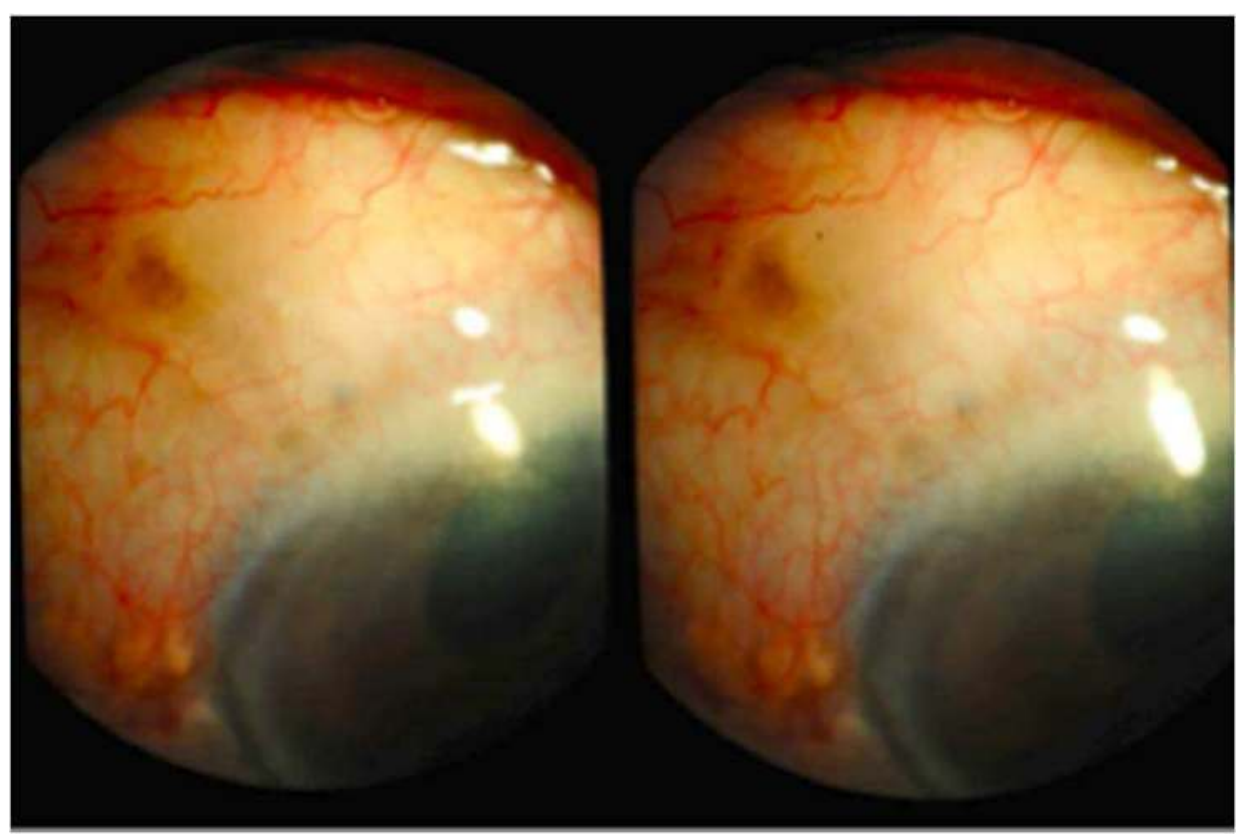

Fig. 23. Two MTF tracks were made in this case of complicated PCIOL with vitreous in the anterior chamber. This picture is 1 month after surgery.

The film of the above patient is here:

http://www.youtube.com/watch?v=B-C8PLw4BWs

\section{Postoperative management}

Postoperatively, there is a tendency to shallow anterior chamber. The pupil is kept contracted with pilocarpine for a few weeks, till a balance occurs between the AC and the subconjunctival fluid space, and the chamber regains normalcy. Being a small channel, there is reduced attraction for the iris to block it on the inside. But it does happen every now and then and the IOP goes up again. Every patient is advised about this possibility, so that he can rush back for management. He is provided an emergency supply of diamox. Rarely, an early block can occur with a speck of blood.The diagnosis is easy - the anterior chamber is deep. There may or may not be pupil peaking. However the IOP is high. Gonioscopy and OCT can demonstrate the block. The block is cleared by YAG laser as follows.

1. A shot may be made inside the track/channel. A small cavitation bubble arising there pushes the iris out in to the AC.

2. The iris itself may be displaced with one YAG laser shot.

The fluid starts moving freely as before. However there is less tendency to shallowness of the anterior chamber, since during these few hours or a day or two, resistance has developed under the conjunctiva, which prevents quick flow of the fluid. Early YAG laser management is like " a stitch in time saves nine". Delay of many days can let the iris develop adhesions. The internal block can also be broken with a 30 guage cannula, passed through a stab incision. 

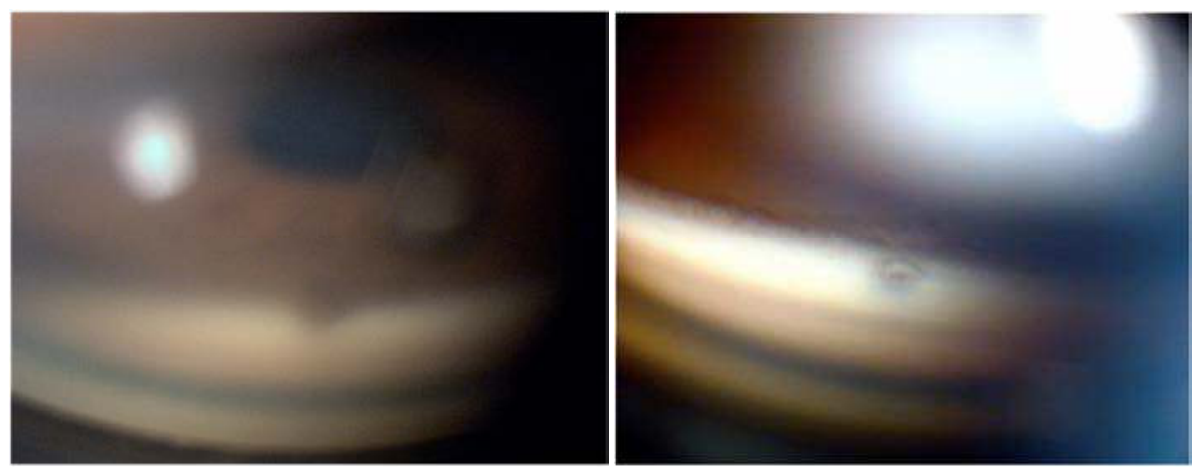

Fig. 24. An internal iris plug blocks the MTF channel, completely stopping the aqueous flow. This is restored with a YAG laser shot. A prominent bleb is formed within minutes.

The following two pictures show OCT of the same case before and after YAG laser management of the iris-block.
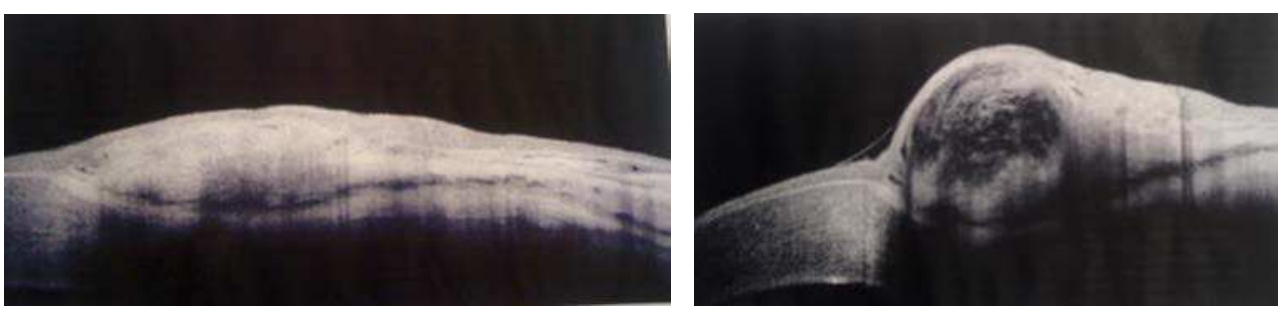

Fig. 25. OCT before and after YAG application the released aqueous balloons up the subconjunctiva.

\section{Microtrack Filtration according to Kiranjit}

Kiranjit Singh has made an important modification of MTF. He starts MTF about $0.5 \mathrm{~mm}$ to $0.75 \mathrm{~mm}$ posterior to the limbus and the track is taken to the clear cornea about $0.75 \mathrm{~mm}$ anterior to the limbus. This longish tube offers some resistance to the free passage of aqueous. The internal opening being more anterior, there is less attraction for the iris. If the internal blockage does occur, it is easy to clear. A film on MTF Kiranjit version can be seen here: http://www.youtube.com/watch?v=LpWdavV4XQM

\section{Results of Microtrack Filtration}

About $30 \%$ patients need freeing of the iris from the internal opening with YAG laser. If the anterior chamber is shallow, a YAG peripheral iridectomy is done. If these minor secondary procedures are considered as part of the postoperative management, then primary success rate easily tops $95 \%$. One in 20 cases needs reoperation to overcome outside scarring.

\section{Crossed linked sodium hyaluronate and TCTCF and MTF}

The slow absorbing crossed linked sodium hyaluronate is an interesting idea. Recently, the author (DS) has used it in many cases of MTF and one case of TCTCF. The device is placed/injected over the filtration track, where it prevents excessive movement of the aqueous. The anterior chamber is better controlled and there is little tendency for the iris to block the track. The patients are discharged in 2-3 days. The following film shows the use of 
this device in a patient who had just undergone phako-surgery and lens implantation and who additionally needed a filtration procedure.

http:/ / www.youtube.com/watch?v=eW9sHukLOjM

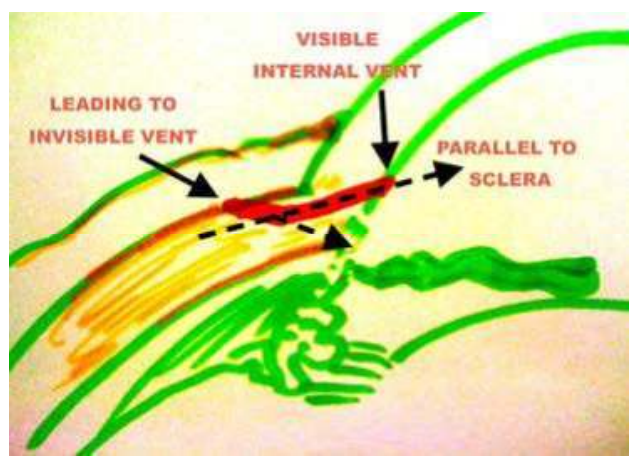

Fig. 26. A diagram to show that ablating the sclera-limbus-cornea parallel to the scleral surface, takes the Fugo blade tip to that point, which can be seen through slit lamp microscope without a gonio lens.

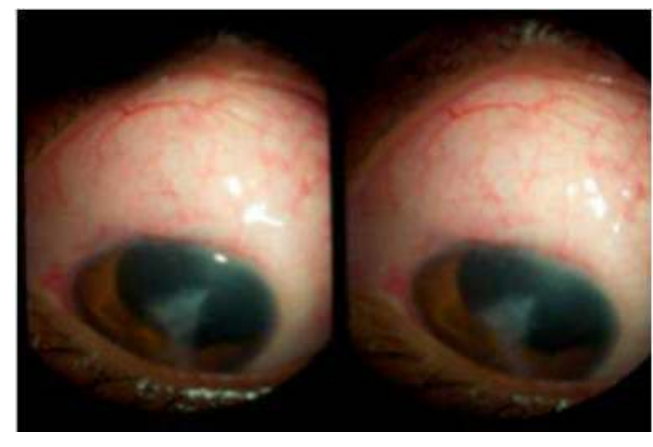

Fig. 27. Age 23, a case of traumatic aphakia with no posterior capsule. MTF-K was done 4 hours earlier. There is no iris in the area. The bleb is well formed and so is the anterior chamber.

\section{Other Fugo blade glaucoma procedures}

The following are the other filtration procedures that can be done with Fugo blade:

\section{Non-perforating filtration surgery (NPGS), Singh version}

The technique is totally different from "deep sclerectomy" and viscocanalostomy. The rationale of NPGS (Singh)technique is as follows. If we follow the surface of the ciliary body towards the cornea, we shall encounter the wider proximal end of the canal of Schlemm. NPGS is the obvious choice whenever it is essential to avoid opening the anterior or the posterior chamber, for example a case of trauma causing angle recession, dislocation of the lens and disturbance of the vitreous, when the emergency needs are a control of intraocular pressure. There are a lot more situations which call for a NPGS approach.
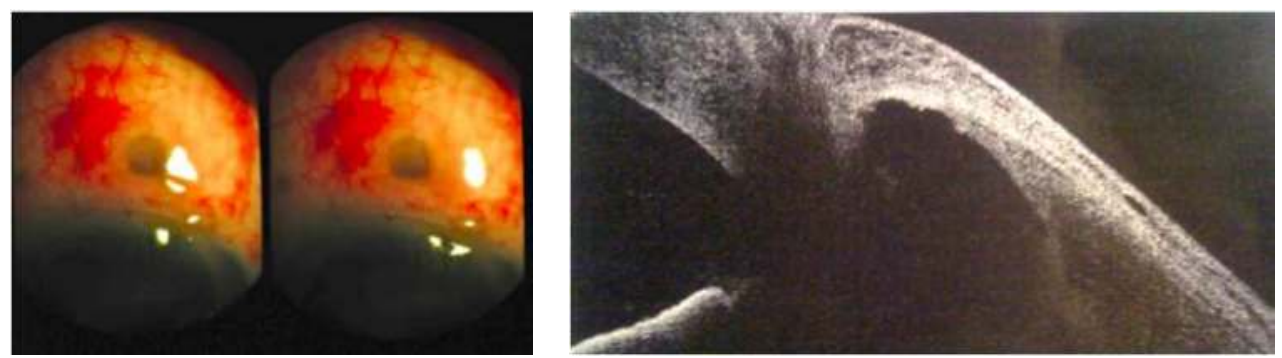

Fig. 28. NPGS in a case of traumatic angle recession, dislocated lens and vitreous disturbance. The $3 \mathrm{D}$ picture of the bleb and the OCT picture were taken one day after surgery.

The film of the above case can be seen here http://www.youtube.com/watch?v=heCpx9mJ434 
The surgery is easy. The conjunctiva is detached from the limbus. Transillumination is done to define the anterior end of the ciliary body. The canal of Schlemm is just anterior to it. A 1 $\mathrm{mm}$ plus scleral pit is made such that the gray/dark ciliary body becomes visible. The pit is made with 300 or 500 micron tip of Fugo blade at low to medium energy. The Fugo blade tip is then directed towards the cornea, at the depth of the pit. It soon ablates through the wider posterior end of the canal of Schlemm, which shows as a gush of aqueous. The anterior chamber remains well formed. Nothing further needs to be done. The conjunctiva is sutured back to the limbus. The patient is fit to be discharged after a few hours, with antibioticsteroid drops to be instilled 6 times a day.

\section{$\mathrm{Ab}$ interno transciliary filtration}

$\mathrm{Ab}$ interno filtration is indicated when ab externo approach is extremely limited due to scarring and shortage of virgin conjunctiva. It should be made sure that this virgin conjunctiva is continuous towards the fornix, if not side ways. To facilitate surgery the anterior chamber is deepened with healon. A $1.5 \mathrm{~mm}$ pocket incision is made in midperipheral cornea.A curved 300 micron Fugo blade tip is passed under the iris, through the ciliary body and sclera to appear under the already raised conjunctiva.

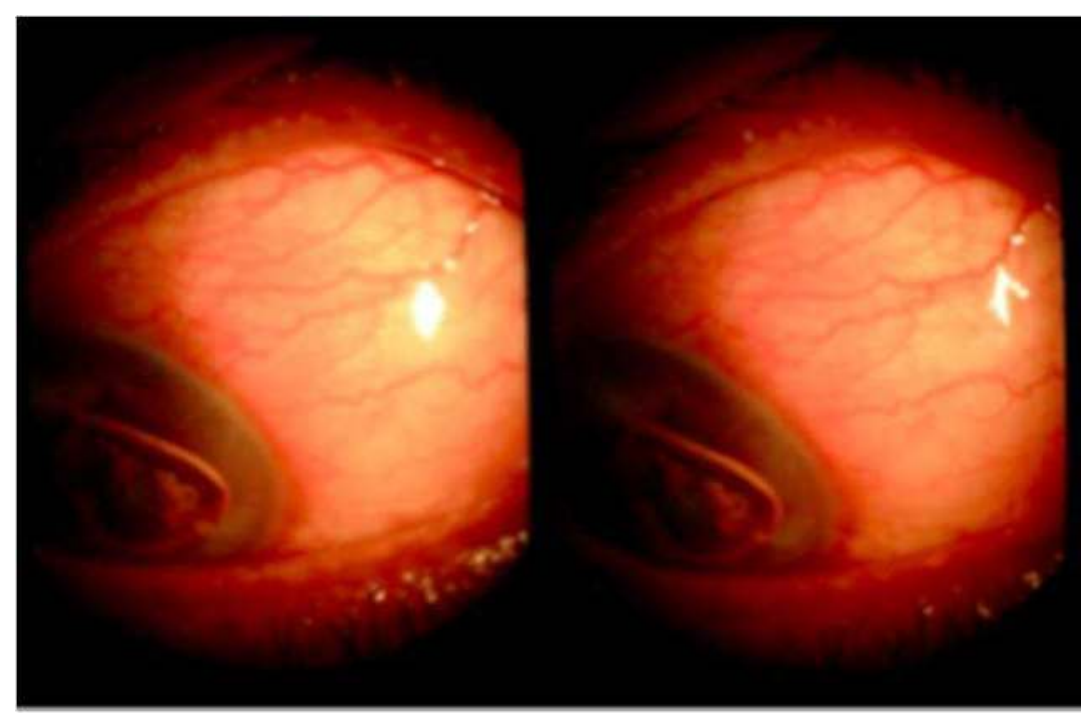

Fig. 29. Ab interno TCF was done with a 300 micron tip, in this case of painful disfigured blind eye with very high intraocular pressure. A nice bleb is formed.

\section{Fugo blade iridotomy}

Pupil block glaucoma whether phakic or pseudophakic can be helped by iridotomy. In a black eye (thick iris) a YAG laser iridotomy does not work. It may be needed to combine iridotomy with a filtration. It is done as follows. A 100 micron tip is introduced through a corneal pocket incision. As it touches the iris, it is momentarily activated at high energy. A micro iridotomy is produced instantly. It may be done at more that one place through the same micro incision. 


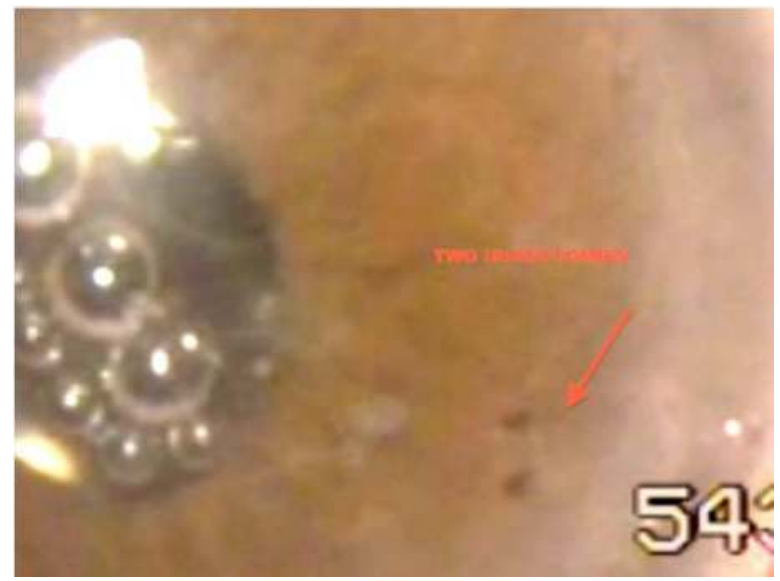

Fig. 30. The Fugo blade tip is touched to the iris and activated. Iridotomy occurs instantly. Two iridotomies were done in this case.

\section{Fugo blade glaucoma surgery in different situations}

\section{Acute congestive glaucoma}

A film on TCTCF in a case of acute glaucoma, with IOP of $50 \mathrm{~mm}$ is shown here: http://www.youtube.com/watch?v=tgRfCqI7jug

\section{Phakomorphic glaucoma}

The following film shows TCTCF in a case of phakomorphic glaucoma. http://www.youtube.com/watch?v=wSWrIr7Jesc

\section{Angle recession glaucoma}

Traumatic angle recession cases present as acute emergencies. We have two choices- MTF and NPGS. Both are best done with Fugo blade.
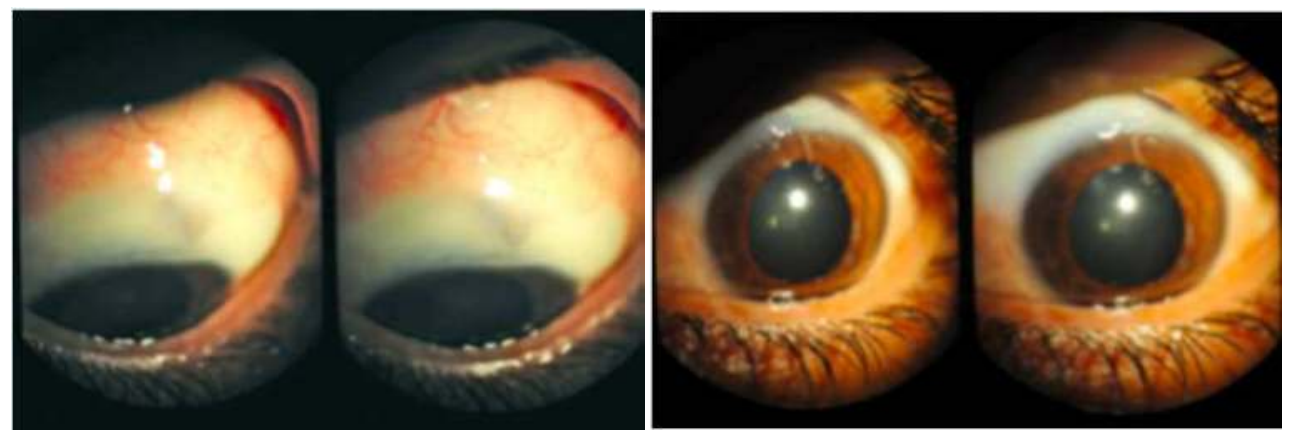

Fig. 31. Angle recession glaucoma operated 1.5 years back by MTF.The bleb shows some pigment, derived from tissues damaged by trauma. The IOP is $10 \mathrm{~mm}$, form the initial 37 mm under treatment. 


\section{Buphthalmos}

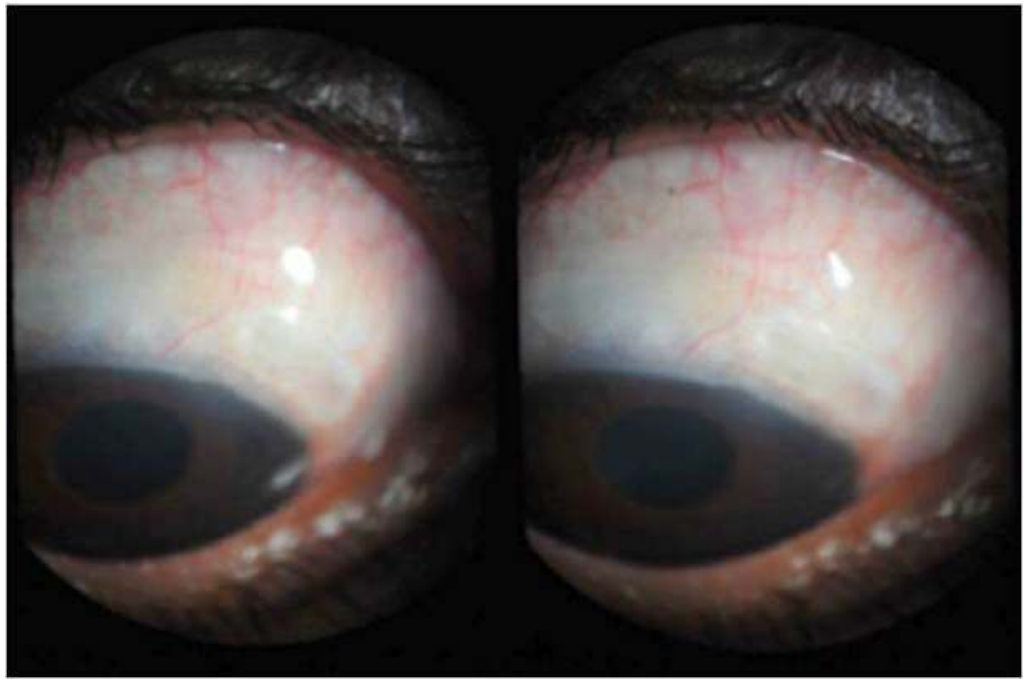

Fig. 32. A case of failed TRAB for buphthalmos. MTF was done up and out.4 years postoperative picture. IOP is $12 \mathrm{~mm}$ from the earlier $41 \mathrm{~mm}$.

A film on MTF in buphthalmos is seen here:

http://www.youtube.com/watch?v=XKQ9-JnBx9I

\section{Uveitic glaucoma}

A case of uveitic glaucoma following PCIOL implantation was treated by MTF: http:/ / www.youtube.com/watch?v=4lEsUvG7dEg

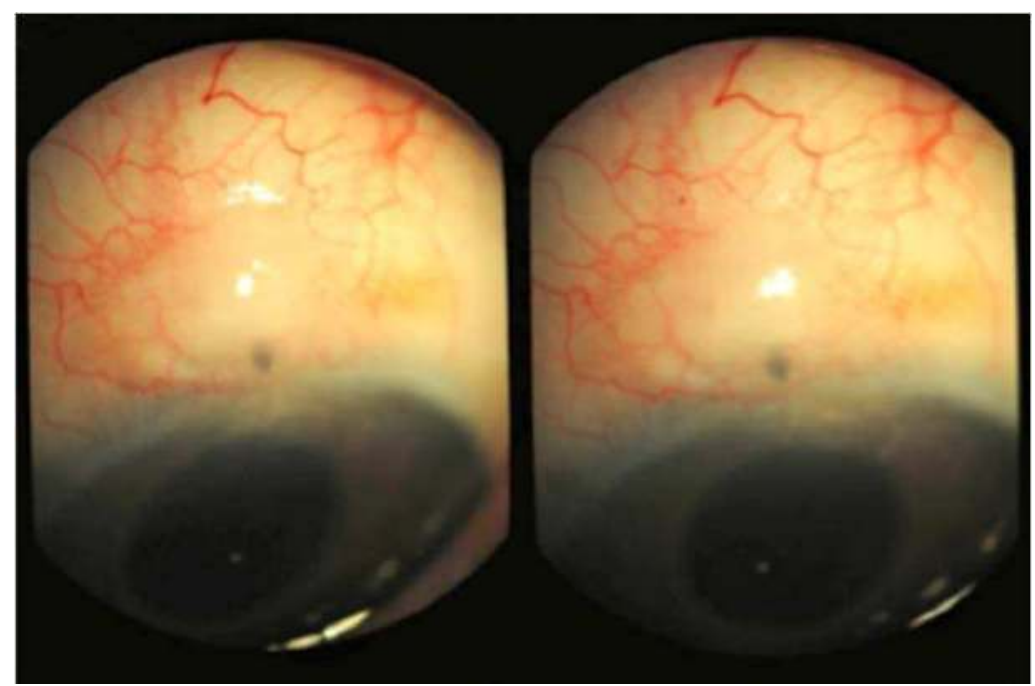

Fig. 33. The same patient as in the film after 3 months. 
Traumatic blackball hemorrhage glaucoma

A film on the procedure can be seen here: http://www.youtube.com/watch?v=yrn45ZqyB58

\section{Pseudophakic pupillary block glaucoma}

Through a $0.7 \mathrm{~mm}$ pocket incision one or more iridotomies are made to clear the block. If need be MTF or TCTCF surgery is done.
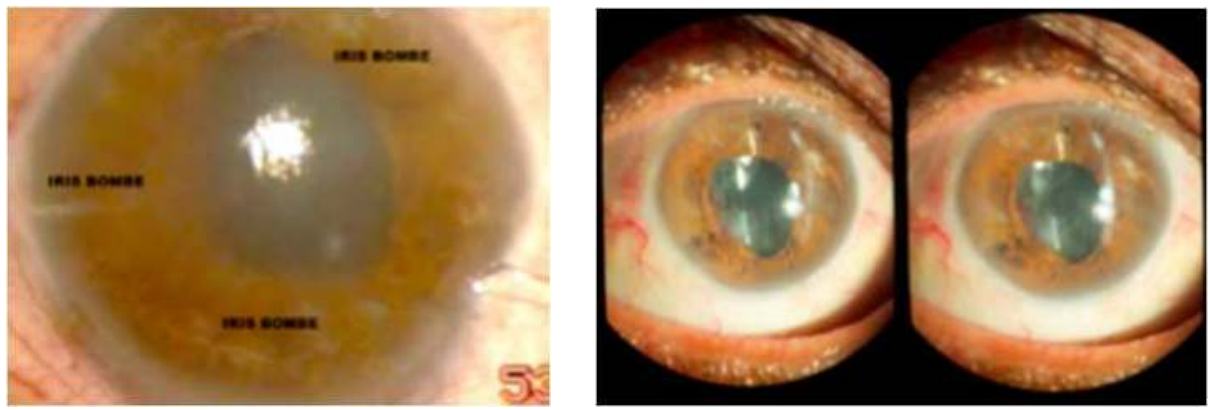

Fig. 34. The patient had a PCIOL, pupil block, iris bombe and IOP in fifties. The upper limbus had scarring. Therefore, MTF was done at $8 \mathrm{O}^{\prime}$ clock. Two months later, he had a deep anterior chamber and an IOP of $10 \mathrm{~mm}$.

Here is the film of the patient shown above:

http:/ / www.youtube.com/watch?v=8R_n729PWno

Here is another film showing Fugo blade iridectomy and TCF in a case of pseudophakic pupillary block glaucoma:

http://www.youtube.com/watch?v=HTviROEmKuc

\section{Glaucoma in deformed anterior segment}

In this group, there are adherent leucoma, anterior staphyloma and ciliary staphyloma. The aim is to save whatever vision is left. TCTCF alone or aided by MTF is needed. At other times MTF is enough.

http://www.youtube.com/watch?v=wgvHJLcq2Rs

\section{Sturge Weber glaucoma}

See TCTCF being performed in this case:

http:/ / www.youtube.com/watch?v=2jrRYOl6dbM
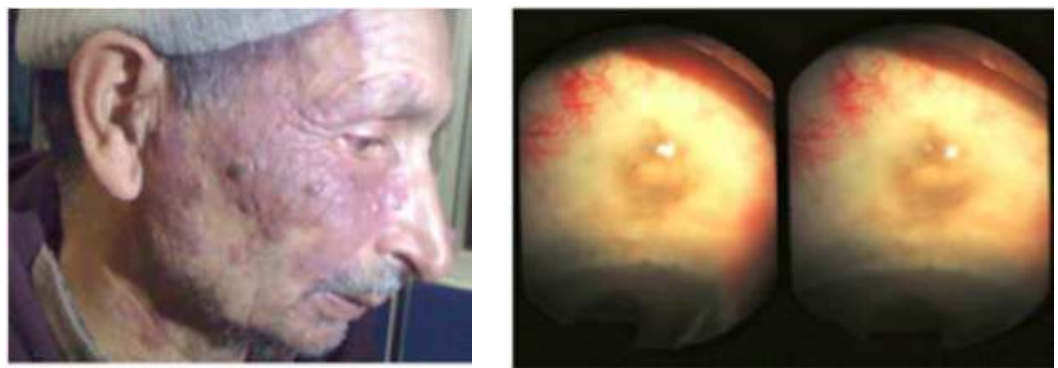

Fig. 35. Sturge Weber syndrome case three months after TCTCF. 


\section{Management of tenon cyst.}

Tenon cyst is often seen following glaucoma surgery. Surgical intervention is sometimes needed. Our approach with Fugo blade is as follows. The conjunctiva is punctured with Fugo blade 100 micron tip about $1 \mathrm{~mm}$ from any easily accessible edge of the cyst. Subconjunctiva is ballooned around the cyst with saline followed by healon. A 300 micron Fugo blade tip is used to open in to the cyst. If cavitation air bubbles are seen to enter the anterior or the posterior chamber, it means that the inner connection is intact. As the tip is withdrawn, the aqueous starts draining. However at this stage, the aqueous movement is stopped by injecting healon in to the cyst and in to the anterior chamber. Following this, the wall of the tenon cyst is systemically destroyed, by repeated thrusts of 300 micron activated tip. A 30 gauge cannula is then swept in every direction to verify tenon wall destruction. If tenon cyst did not show any communication with the interior, this is the time to establish that channel, in to either chamber. In TRAB cases the subscleral space is cleared of adhesions, simply by getting under the scleral flap with activated 300 micron Fugo blade tip, and anterior chamber channel is re-established. Mitomycin C, $0.01 \%$ is injected around the ablated edge of the tenon cyst. The single conjunctival entry point is closed with a suture.

Tenon cyst management in a complicated diabetic case who had undergone VR surgery with silicone oil injection is shown here:

http:/ / www.youtube.com/watch?v=UMoviTAWyVs
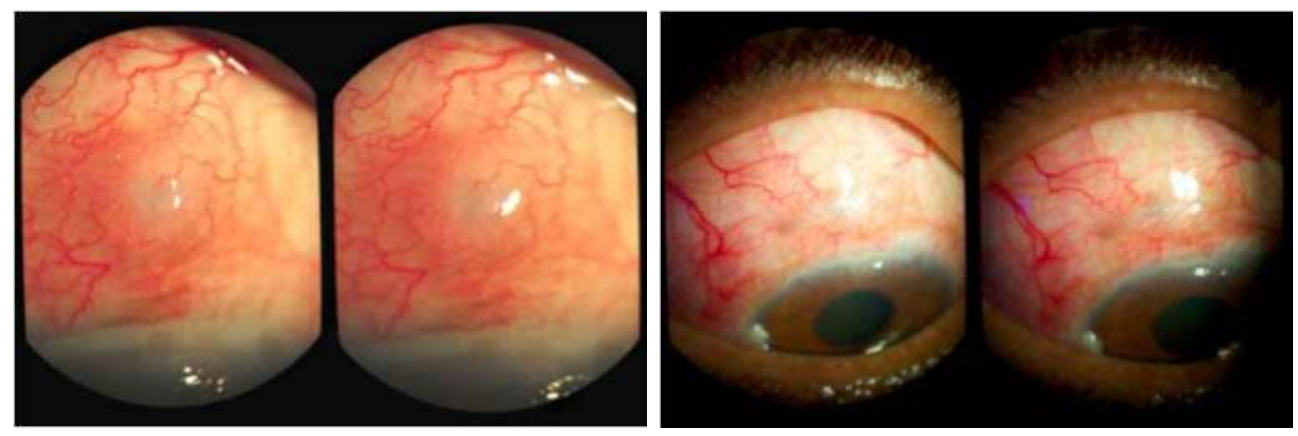

Fig. 36. A case of neovascular glaucoma and VR surgery, who developed tenon cyst following TCTCF. The pictures show the tenon cyst area before and one month after surgery. The IOP is $17 \mathrm{~mm}$.

\section{Glaucoma valve surgery}

Fugo blade can help glaucoma valve placement in many ways. A gutter may be made in the sclera, or even a closed track/tunnel through the sclera, right in to the anterior chamber, to place and fix the tube.

Glaucoma valve fails when it gets covered with thick fibrous tissue/tenon cyst.. The valve function can be restored easily. An incision is made right over the valve, cutting both the conjunctiva and the wall of tenon cyst. The cyst is excised over a wide area and the conjunctiva is sutured back.

\section{Neovascular glaucoma}

Neovascularization of the iris is seen in numerous conditions, the most important being diabetes. The IOP may be in fifties. The patient may have poor vision or a painful blind eye. 
All the pathology is seen on the surface of the iris and the angle. None of the studies has shown new vessel formation on the ciliary body or the posterior surface of the iris. TCTCF does not involve iridectomy. Subconjunctival placement of mitomycin is important.

Surgery of neovascular glaucoma:

The following three films are contributed by Prof.Vinod Kumar of Moscow (Russia) http:/ / www.youtube.com/watch?v=xnWa2gXbirk

http://www.youtube.com/watch?v=22J7abbmO5A

http://www.youtube.com/watch?v=qoJcGDLh4vw

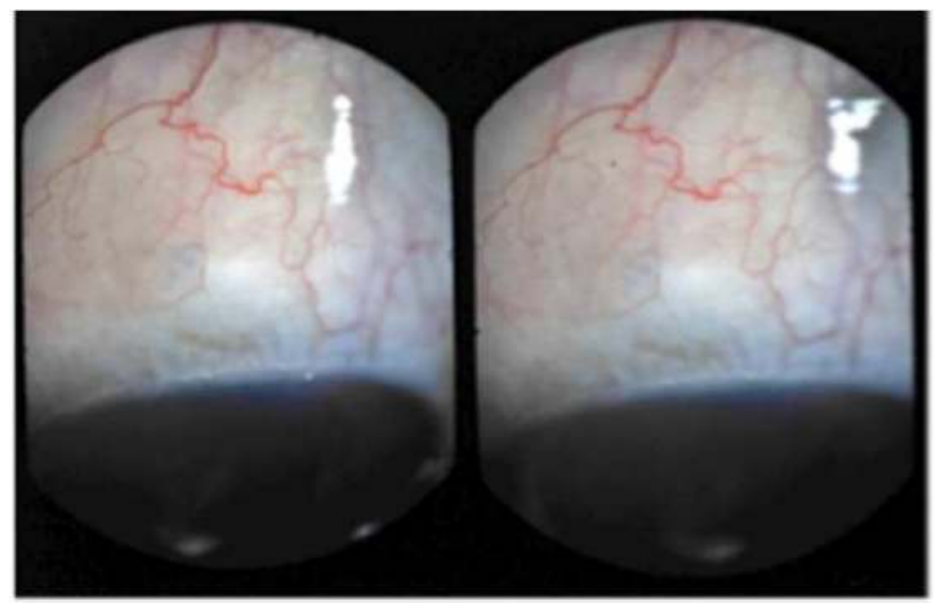

Fig. 37. Neovascular glaucoma. TCTCF 6 months after surgery. MMC $0.04 \%$ was used to balloon the subconjunctiva after surgery. The conjunctiva appears to be healthy and normally vascularized

\section{VR Surgery and glaucoma}

The choice of surgery depends upon the surgeon's assessment in each individual case. We can choose between Fugo blade NPGS, MTF, open TCF, TCTCF as stand alone techniques, or combining techniques. For example MTF + TCF, NPGS+MTF or NPGS+TCF. Failure is frequent and additional medication is often necessary.

The film below shows TCTCF in a case of pars plana lensectomy and vitrectomy: http://www.youtube.com/watch?v=IEA2YFMsfJQ

\section{Low tension glaucoma}

These are the patients with ocular pressure below 20, but have advanced disc and field changes. TCTCF or MTF are easy, least traumatic and least tissue reactive means of lowering intraocular pressure. Our experience is limited to less than 10 patients.

TCF surgery in a case of low tension glaucoma is shown here:

http:/ / www.youtube.com/watch?v=jz-qFeyhzz8

\section{Bleb leakage}

Fugo blade helps in the management of a leaking filtering bleb. The following patient had a leaking bleb after trabeculectomy.

http://www.youtube.com/watch?v=ICa1cZ-OL68 


\section{Concluding remarks}

An estimated 80 million glaucoma patients worldwide and thousands being added every day are a challenge to the ingenuity of the glaucoma surgeons and the producers of glaucoma medications and devices. The understanding of the conjunctival and uveal lymphatics shall encourage us to reduce trauma during surgery. Fugo blade is a new tool of a totally different nature, that has some merits. We should keep a watchful eye on the utility of cross linked sodium hyaluronate. There is a long way to go in glaucoma surgery to match with the successes that have been achieved in the fields of lens/cataract and refractive surgery.

\section{References}

[1] Allingham,R.R.(2005) Shield's Textbook of Glaucoma, fifth edition:p.568.

[2] Atwal A. 'Atwal's Balanced Approach' for Glaucoma Filtration Surgery Presented. Ocular Surg News. 2005; 19:64-66.

[3] Bethke WC. A New Clue to Lymphatic Drainage? Review of Ophthalmology. 2002; 9, 3

[4] Dow T, Devenecia G. Transciliary Filtration (Singh Filtration) with the Fugo Plasma Blade. Ann Ophthalmol. 2008; 40,1; 8-14

[5] Eisenstein P. World's Smallest Knives. Popular Mechanics. 2003; 180, 10; 56-8.

[6] Fine IH, Hoffman RS, Packer M. Highlights of the 2002 ASCRS Symposium, Part I. Eyeworld. 2002;7,7:38

[7] Fugo R. Regarding Transciliary Filtration. Tropical Ophthalmology. 2002; 2, 1; 7-8.

[8] Fugo R. Transciliary Filtration Procedure Offers New Approach to Glaucoma. Ocular Surg News. 2005; 16,6; 18-19.

[9] Fugo RJ. Trans-ciliary Filtration. Video Journal of Current Glaucoma Practices. SeptDec. 2007. Vol. 1, No. 2.

[10] Fugo RJ. Plasma blade has several applications in ophthalmic surgery. Ocular Surg News. Dec 25, 2009

[11] Guttman C. Anterior segment tool proves ideal for many applications. Ophthalmology Times. 2005;30,2;14,16.

[12] Guttman C. Transciliary filtration provides improved safety and simplicity. Ophthalmology Times. 2005;30,3; 28.

[13] Izak AM, Werner L, Pandey SK, Apple DJ, Izak MGJ. Analysis of the capsule edge after Fugo plasma blade capsulotomy, continuous curvilinear capsulorhexis, and canopener capsulotomy. J Cataract Refract Surg. 2004;30, 12;2606-2611.

[14] Kent C. Revealed: the Eye's Lymphatic System. Ophthalmic Manage. 2002; 6, 5: 114.

[15] McGrath, D. Fugo Blade effective tool for multiple surgical applications. Eurotimes. $2008 ; 13,6: 43$.

[16] Peponis V, Rosenberg P, Reddy SV, Herz JB, Kaufman HE. The Use of the Fugo Blade in Corneal Surgery: A preliminary Animal Study. Cornea. 2006; 2: 206-8.

[17] Pollack,I.P.(2000).Ocular Surgery News.Europe/Asia Pacific Edition,July 1,2000.

[18] Ronge L. How to Use the Fugo Blade. EyeNet. 2003; 7, 9; 23-4.

[19] Roy,H.,Singh,D.,Fugo.R.Ocular Applications of Fugo Blade.(2010) Lippincots Williams and Wilkins,p.77 -126.

[20] Scimeca G. Phaco with Transciliary Filtration an Alternative to Triple Procedure. Ocular Surg News. 2005; 23,11; 58. 
[21] Singh D. Singh Micro-Filtration for Glaucoma; A New Technique. Tropical Ophthalmology. 2001; 1, 6: 7-11.

[22] Singh D, Singh K. Transciliary Filtration Using the Fugo Blade. Ann Ophthalmol. 2002; 34,3; 183-87

[23] Singh D. Letters: Conjunctival Lymphatic System. J Cataract Refract Surg. 2003; 29, 4; 632-3.

[24] Singh D. Transciliary Filtration \& Lymphatics of Conjunctiva- A Tale of Discovery. Tropical Ophthalmology. 2002; 2, 1; 9-13

[25] Singh D, Singh RSJ, Singh K, Singh SK, Singh IR, Singh R, Fugo RJ. The Conjunctival Lymphatic System. Ann Ophthalmol. 2003;35, 2;99-

[26] Singh D .Microtrack Filtration. Annals of Ophthalmology 2002;34,3;183-187

[27] Trivedi RH, Wilson Jr. ME, Bartholomew LR. Extensibility and scanning electron microscopy evaluation of 5 pediatric anterior capsulotomy techniques in a porcine model. J Cataract Refract Surg. 2006; 32, 7:1206-13.

[28] Winn CW. Broad applications seen for electrosurgical instrument. Ocular Surg News. 2001; 19, 11: 45-46

[29] Yeni $\mathrm{H}$ et al. Identification of lymphatics in the ciliary body of the human eye: A novel "uveolymphatic" outflow pathway.Experimental Eye Research 89 (2009) 810-819 


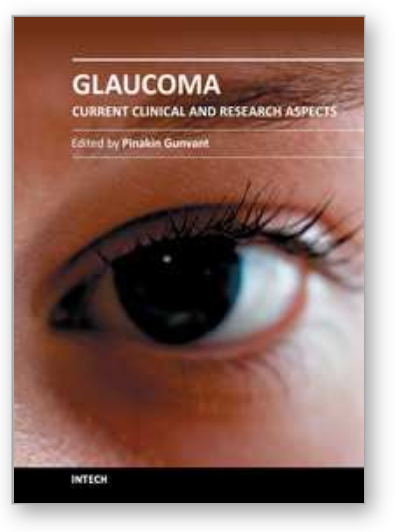

\author{
Glaucoma - Current Clinical and Research Aspects \\ Edited by Dr. Pinakin Gunvant
}

ISBN 978-953-307-263-0

Hard cover, 376 pages

Publisher InTech

Published online 09, November, 2011

Published in print edition November, 2011

This book summarizes current literature about research and clinical science in glaucoma and it is a synopsis and translation of the research conducted by individuals who are known in each of their respective areas. The book is divided into two broad sections: basic science and clinical science. The basic science section examines bench- and animal-modeling research in an attempt to understand the pathogenesis of glaucoma. The clinical science section addresses various diagnostic issues and the medical, laser and surgical techniques used in glaucoma management.

\title{
How to reference
}

In order to correctly reference this scholarly work, feel free to copy and paste the following:

Daljit Singh and Richard Fugo (2011). Glaucoma Surgery with Fugo Blade, Glaucoma - Current Clinical and Research Aspects, Dr. Pinakin Gunvant (Ed.), ISBN: 978-953-307-263-0, InTech, Available from:

http://www.intechopen.com/books/glaucoma-current-clinical-and-research-aspects/glaucoma-surgery-withfugo-blade

\section{INTECH}

open science | open minds

\section{InTech Europe}

University Campus STeP Ri

Slavka Krautzeka 83/A

51000 Rijeka, Croatia

Phone: +385 (51) 770447

Fax: +385 (51) 686166

www.intechopen.com

\section{InTech China}

Unit 405, Office Block, Hotel Equatorial Shanghai

No.65, Yan An Road (West), Shanghai, 200040, China

中国上海市延安西路 65 号上海国际贵都大饭店办公楼 405 单元

Phone: +86-21-62489820

Fax: +86-21-62489821 
(C) 2011 The Author(s). Licensee IntechOpen. This is an open access article distributed under the terms of the Creative Commons Attribution 3.0 License, which permits unrestricted use, distribution, and reproduction in any medium, provided the original work is properly cited. 